\title{
THE RESTORATION OF A BELl P-39Q AiraCobra AIRCRAFT
}

Rauni Valtonen \& Hannu Valtonen

On June 17, 1944 a formation of four — according to some sources five-Bell P-39Q fighter aircraft lost their bearings. The great Soviet offensive on the Karelian Isthmus was in progress and the weather was cloudy and rainy. The formation in which the Airacobra "26", the subject of this restoration report, flew got lost and split up. The Russian regiment to which the the fighters were attached is not known but the higher command is thought to be the 2nd Leningrad Guards Fighter Corps (II Gv.IAK). One of the aircraft landed some six kilometres north-west of Jantama village at Syväri, another at Pätsinsuo in Ylä-Uuksu in Salmi parish, north-east of Lake Ladoga (P-39Q15-BE, USAAF 44-2664, No. "26") and two at Pikkusuo in Marinkylä in Inkeroinen (P-39Q-20-BE, USAAF 44-3255 No. "25" and P-39Q-15.BE, USAAF 44-2092 No. "20"). The fighters were a part of the U.S. war material aid to the Soviet Union. An enormous number of Airacobras was delivered, in total 5707 aircraft.

There is an anecdote about the forced landing at Inkeroinen. The Finnish Air Force Radio Intelligence Company had been enlarged to battalion size and consequently the personnel had been supplemented from General Headquaters' Radio Intelligence battalion. In a case like this, the supplying staff unit often gets rid of its less desirable personnel. On June 17th, 1944, two Russian aircraft appeared at Pikkusuo and made stylish belly landings there. The bog was also the location of a direction-finding station of the Radio Intelligence Battalion. The man on duty was shocked when he saw two Russians approaching the hut with pistols in their hands - the station personnel had been disarmed because of their reckless behaviour (the nation's top intelligence could not be trusted to carry guns). He telegraphed quickly to the main station, explained the situation and asked: What shall I do? The main station gave a useful answer: Escape through the window opposite! The man did as he was told and when the Russians saw the Finn running across the bog, they headed to the opposite direction. The confrontation was avoided - 
110 however, the unfortunate Russians had to be eliminated the same evening somewhere near Hamina, as they were not willing to surrender. Such is the cruelty of war.

The Airacobra which had landed at Syväri was destroyed before the Finnish retreat, the other three were transported to the State Aircraft Factory at Tampere. There it was noticed that because of the belly landings, the under surfaces were damaged and the propellers broken - there was no point in trying to repair the aircraft. The wheels, armament, radio equipment and instruments were dismantled and the aircraft ended up in the Finnish Air Force depot in 1946. Parts of one aircraft were put on one side to await the foundation of an aviation museum.

\section{THE DEFINITION OF THE LEVEL OF RESTORATION}

Before starting the restoration, the museum staff discussed what the final result should look like. In principle it was decided that the aircraft would be shown as it appeared when it was $15 \mathrm{~cm}$ above the surface of Pätsinsuo and going down. The decision to show it this way was reached based on:

- the available information: manuals and drawings

- the condition of the existing parts

- the resources such as skills, tools, raw materials and available funds. Money - or the lack of it - was a decisive factor. The museum's limited funds had an effect on the purchase of parts. Obviously almost anything would have been available if only the museum had had enough money, for example, a propeller in flying condition would have cost about FIM 100000.
- the time available was also decisive. Sometimes the "military comfort factor", or laziness, had to be utilized: how much effort should be used to restore an object for which no information can be found or which is located inside the aircraft and is therefore not visible. Should a system be made to function or not? However, the use of this method must be strictly limited.

- a damage inventory had to be made: forced landing, dismantling, transportation, storage, corrosion, mischief.

- a list of defects also had to be made.

- the stenciled markings on the aircraft were a problem in themselves, as was the attitude towards the original, possibly very poor, painting.

The alternatives were:

- major repair and repainting meaning that a lot of the original is lost and /or

- minor repair and repainting meaning that more of the original is preserved ( the "military comfort factor" should be avoided) and finally

- the museum director's opinion that the aim should not be to produce something that was airworthy but rather a museum object that was suitable for display. Not every small dent needed to be repaired. The manner in which our neighbours met their "painting norms" should be accurately taken into account.

Problems discovered:

- all measures in the aircraft and its drawings were in American inches as were the bolts, nuts, screws, wrenches, taps, dies, etc. Conversion charts to the metric system were needed and had to be adopted mentally; the museum workshop stores 
had to be sorted according to the correct measures. On the positive side, thanks to American standardization, suitable nuts and bolts are still available.

- staff had to learn how to read drawings from microfilm before they could be used.

- the construction methods for parts and sub-assemblies made of different materials had to be learned by experimenting in practice with the aid of drawings and scrap parts and the museum's few tools and raw materials.

- if the knowledge is discovered during the work process, there is no time to check on its correctness and the solution chosen may be the wrong one - the working plan should begin from the raw materials, because substitutes must often be used, either because the material in question is no longer being produced or the museum's resources are not sufficient to cover its purchase or production (e.g. making curved laminated glass or treating duralumin).

- some priorities have to be set for the plane as a whole - what is more and what is less important.

As a whole the restoration demanded considerable dexterity, resourcefulness and an unprejudiced attitude from the personnel. Construction details which required various tricks and solutions were constantly come across - in fact the whole project was a sort of expansion of consciousness.

\section{THE PROGRESS OF THE WORK 1980-82}

The fuselage of the aircraft (AAF 442664), captured in 1944, written off by an order of the day of the Finnish Air Force Commander in 1953 and ordered to be placed in a museum, and the wings from a different aircraft (AAF 44-3255) were moved to hangar No. 2 at Tikkakoski in 1980. The Airacobra fuselage was shown to a Soviet military delegation during their visit in Tikkakoski. The parts were moved to the museum's storage hangar in 1982 , the wings were placed in a position leaning against the fuselage.

\section{4}

Preparatory measures for the future restoration were taken during the autumn by the museum's restoration club which consisted of aviation enthusiasts and by a museum apprentice Ari Piik. However, at this stage there was no pre-determined plan of action. The free labour available was the driving force of the project. A storage rack was built for the wings. The fuselage was dragged out of the hangar corner, the log frame on which it had lain since the war was dismantled and replaced by a pack of pallets to facilitate moving. The engine was removed to be put on display - which revealed another task: the crankcase shape had been pressed into moss which had entered the engine compartment during the belly landing. First the oily moss was removed, then the area was vacuumed, washed with mild solvent and treated with protective agent. At this stage, a preliminary inventory of existing and missing parts was made and was later used when inquiring after missing parts. The activities of the restoration club diminished in the course of time and the project was abandoned for ten years. 
RaUni Valtonen \& Hannu VaLtonen

112

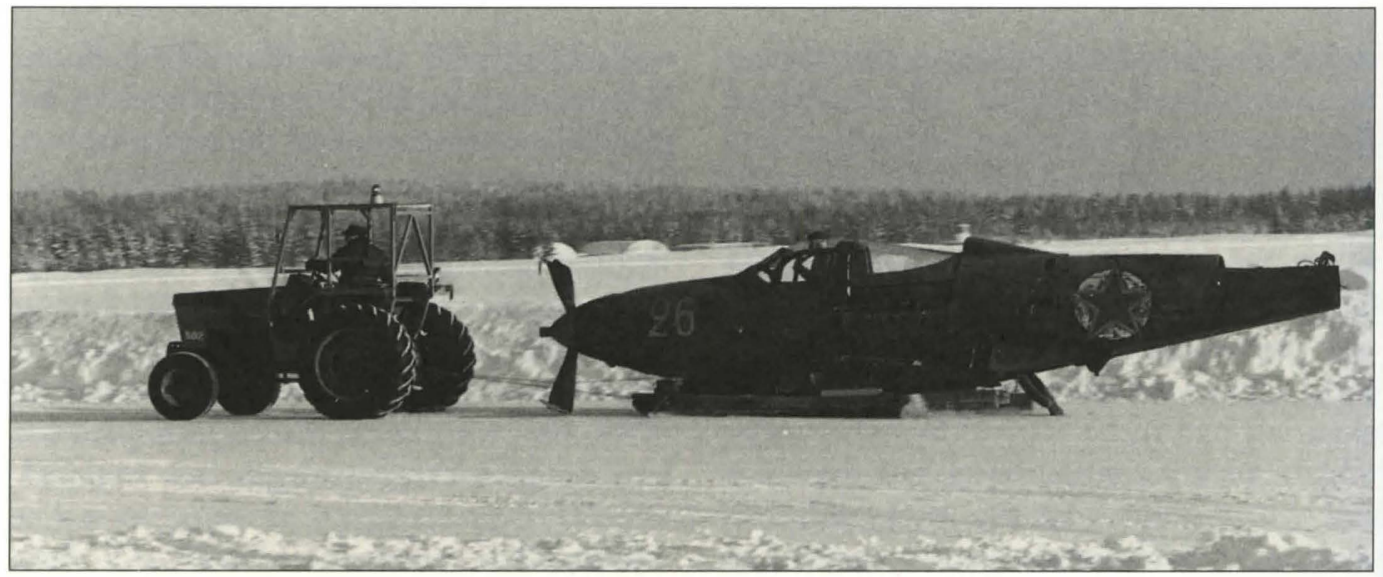

Fig 1. After a couple of years in storage, the Airacobra was aired with its rear hatch open behind a Valmet tractor on February 1st, 1982. During this sleigh-ride it was moved from Hangar I to the museum's storage.

(Bell is the aircraft factory which designed the type, $P$ means pursuit or a fighter, P-39 indicates that it is the 39th fighter type of the U.S Army Air Force, $Q$ is its sub-version, 15-BE indicates that it belongs to the 15th construction series which was built by the Bell factory)

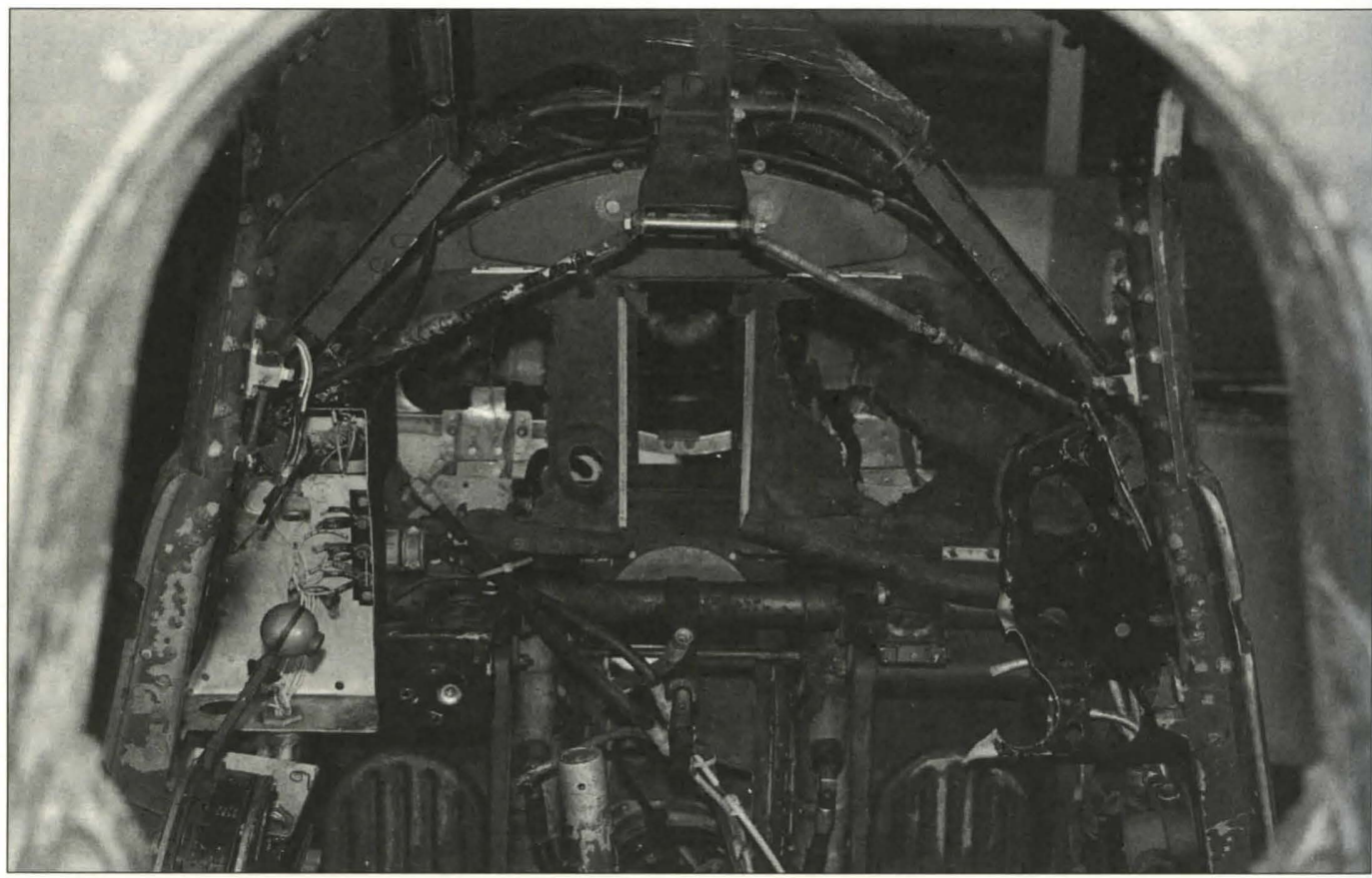

Fig 2. The front part of the cockpit on December 8th, 1995, the instrument panel, instruments and the gunsight were the greatest defects of the "26" at first sight. 
1995

In August the Airacobra wings, tailplane, sheet panels, tires, seat and three spinners, among other things, were taken out of the museum storage hangar. The sheet panels were listed, washed and arranged in crates in the museum and extra parts were removed. Pentti Manninen, an aviation historian from Helsinki, informed the museum that the Smithsonian Institution in Washington D.C. had Airacobra manuals and microfilmed drawings. Airacobra documents from the Finnish Military Archives were received via Mr Manninen.

In September the Airacobra fuselage was transported from the storage hangar to the museum repair workshop where it was first photographed using both black and white and color transparency films. Throughout the project the aim was that general photos, plus slides of the damage and details of parts under treatment should be taken at all stages. A frame equipped with a wheel was constructed in which the fuselage was placed - taking into account the center of gravity. Detachable panels were removed and vacuuming began. The vacuum cleaner container was always checked when it was emptied. Moss, turf, sand and even an unused cartridge were found in the aircraft which had made a forced landing in a bog. Some of the underside panel screws were rusty and broke during removal; there was also some corrosion.

In October, the examination, copying and photographing of the aircraft's stenciled maintenance and safety markings began. The rear fuselage was dismantled. The coolant tank was removed. The parts of the engine intake system were listed.
The repair of buckled sheet metal parts began. The cockpit and the space under it were protected with LPS $3 / 2$. The engine compartment was washed with solvent, the cannon compartment was washed. Microfilmed drawings were ordered from the USA. The propeller blades were removed and sent to Helsinki to be used as patterns in making a fibre glass replica - an airworthy propeller could have been obtained from America, had there been enough money. A composite specialist and a master model aircraft builder, Matti Patteri, promised to make the replica blades free. In November the museum nut and bolt stores, including those donated by Konekorhonen, the local aircraft repair firm, were sorted out by an apprentice. The nosewheel was removed. The fuselage was photographed. Electrical parts, wheel wells and the propeller hub were cleaned.

In December, the specifying and search for the instruments began, at first from our own stores. The museum had FIM 30,000 for the purchase of parts. Correspondence with various suppliers began. Deficiency lists were made.

An article Bell P-39 - a second-rate warbird by the museum's research assistant Timo Heinonen was published in several aviation and defence periodicals.

\section{6}

In January the cockpit-door map case was repaired and rubber mouldings were glued to the window frames. Cardboard patterns were made for the cutting of the cockpit plexiglas panels. Some twenty new sheet metal parts were made for the cockpit, among other things, a firewall behind the pilot's seat. The purchase or making of the 
114 special tools needed was laborious and the Konekorhonen firm also proved helpful in this matter.

In February a drawing was prepared of the cockpit top panels and the building of wooden moulds for the plexiglas panels began. The microfilmed drawings were received from America (\$ 244.00), 16 rolls altogether.

In April the whole restoration project had to be halted because of arrangements for the moving of the museum's stores.

In September in accordance with an earlier agreement for an exchange of aircraft floats, the Norsk Luftfartsenter (Bodø, Norway) supplied the Airacobra fin and rudder, restored from parts of a wreck found in the mountains in Northern Norway. The parts were brought by $\mathrm{Mr}$ Ragnar Johnsen and his wife, Mr Rolf Betten and Mr Ivan Kristensen.

The local weekly newspaper, Jyväskylän Ympäristölehti, published an article Aircraft restoration is a rewarding task on 10 January. Mr James Coffed (Lancaster, USA) supplied photos, drawings and other information about an Airacobra propeller which he owns.

\section{7}

In January a plywood mock-up instrument panel was made for trial fitting. MiG-21F instrument panel switches and cockpit ultraviolet lights which are similar to American parts, were bought from the Finnish Air Force surplus shop in Kasinhäntä.

In February the study of the American microfilmed drawings began. From the beginning the museum research assistant Timo Heinonen has frequently had to ask for help with translating them. The timber for the big cockpit plexiglas panel moulds was ordered from the local joinery shop, Tikkapuu, and the carving began.

The building of the instrument panels started in March. Two instrument panel text plates (Radio Call) were received from the USA.

In May-June the moulding of cockpit handles was practised under the instruction of sculptor Pekka Luukkonen. An engraving machine was borrowed from the Air Force. As all instrument panel markings had to be made with it engraving and lay-out were practised. The control column grip was obtained in an exchange with Mr Robb Hill (Las Vegas, USA).

In September the gunsight was completed, a cockpit side glass panel was fitted and patterns were made for the armoured glass.

In October plexiglas panels were cut and assembled. Konekorhonen's workshop did the curving.

In November-December the big cockpit panel moulds were filled and finished.

\section{8}

The year was spent making sheet metal parts including all the under panels of the fuselage bottom panels, because the original parts had been completely ruined in the belly landing. The wings were moved to the museum repair workshop where treatment began with vacuuming and brushing the inside and giving the outside a light water wash.

In September a copy of a Russian «Field Repair Manual» was received from $\mathrm{Mr}$ Carl-Fredrik Geust.

During the autumn, conservation 
The RESTAURATION OF A BELL P-39Q Airacobra aircraft

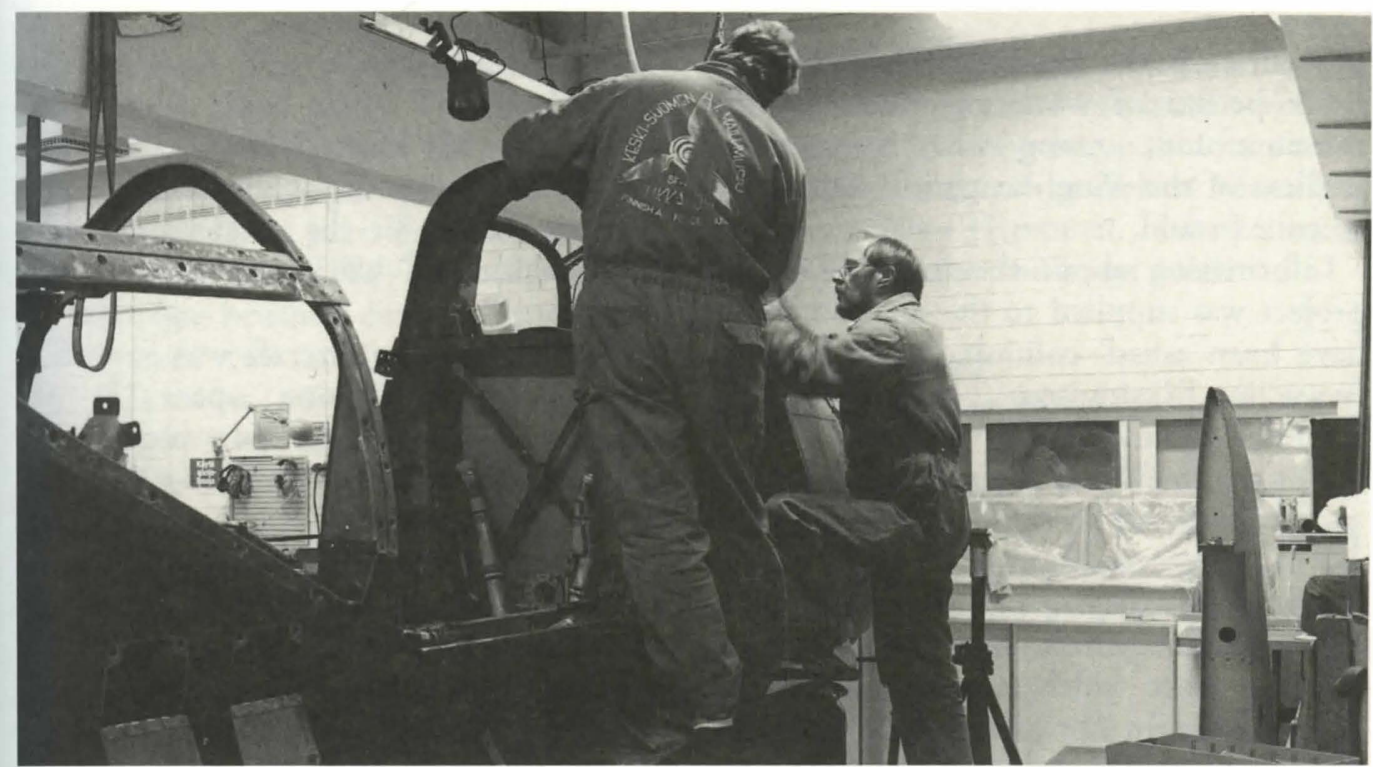

Fig 3. The missing cockpit plastic panels caused a lot of work. At first, large wooden moulds had to be built for pulling them to shape. The photo shows Arvo Hirvonen (left) and Veikko Havimo measuring the canopy in October 1997.

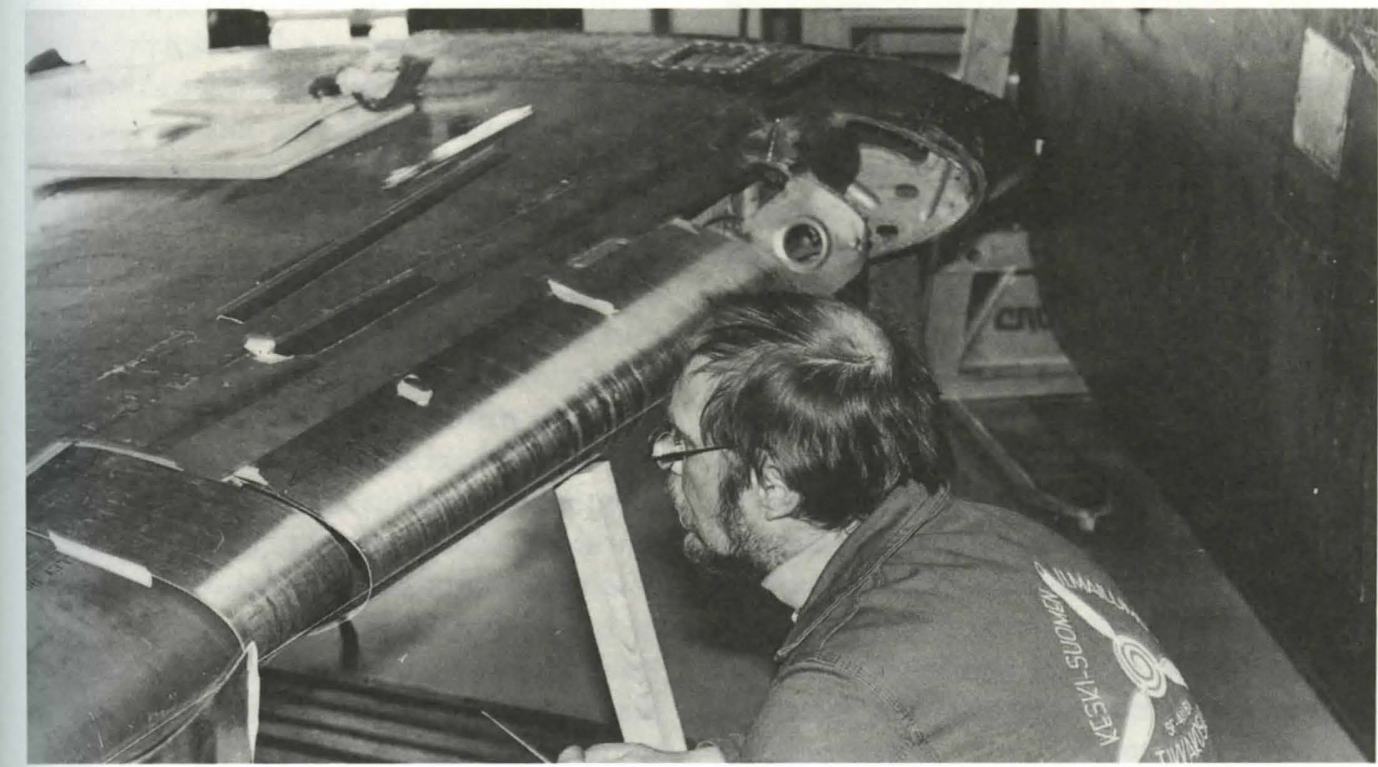

Fig 4. Restorer Veikko Havimo examining the repair of the leading edge of the "cobra's" starboard wing. This was one of the most demanding tasks of the whole restoration. 
116 apprentice Jukka Haakana (Helsinki) was on a period of work experience at the museum and, among other things, cast replicas of the wing navigation lights in a silicone mould.

Information about the progress of the project was supplied to the museum's 'We have been asked' column in the Internet (www.jiop.fi/ksimuseo, maintained in English by Janne Saarijärvi, Vaasa).

\section{9}

Landing gear display supports were made. Wing sheet panels were beaten from Russian sheet which came from the Air Force stocks. In April the industrial polyurethane paint Teknodur was obtained for the new sheet panels. It was tinted with paint which was left over from the painting of the Messerschmitt Bf 109 G-6 on display at Utti, in addition, yellow paint was bought. In the autumn, artist's oil colours were bought for the restoration of the national markings.

In October four instruments and two wing navigation lights were received in exchange from Mr Robb Hill (Las Vegas, USA). The national markings were photographed in colour before and after the repair. Aluminium paint for the fin and rudder was purchased.

In November the cockpit plexiglas panels were drawn. The first attempt to manufacture them by a plastics firm at Vaajakoski failed as the filler separated from the moulds.

$\mathrm{Mr}$ Matti Patteri brought to the museum the fibre glass replica propeller blades he had made.

In December three propeller decals, ordered from the USA, arrived.

\section{0}

In January Mr Matti Närhi (Tikkakoski) supplied ten stencils for the markings, cut in tape. Dope for the propeller, translucent colour and black paste colour were bought.

In February the aircraft was moved to the special exhibition space in the museum and the assembly began. The painting was finished with artist's colours. In larger areas which needed repair, aluminium primer was used. Perfection was not the aim of the paint repairs, instead it was to match the repairs with the general impression. It proved to be difficult to clean the surface of the hand-painted national markings, because the paint adhered poorly, it peeled off and was porous. Cyanoacrylate glue melted it, but did not soften it sufficiently and the edges of the paint coat stood out. Other conservation experts (Paappa, Nikkanen and Wikström) were consulted about the painting of the surfaces.

Polyfilla and car filler were used for filling. New sheet panels were primed with aluminium primer and painted with Teknodur paint made by Teknos and mixed by the restorers themselves. The rudder and fin were also primed with aluminium primer, painted with Teknodur and special aluminium coloured alkyd paint. The peeling spots in the national markings were painted with artist's oil colours, scratches caused in the moving and final assembly were treated with artist's acryclic colours. The top coat of the replica propeller blades was colored resin. They were painted with black translucent paint, the markings with black paste colour and finally they were given two 
coats of dope. The propeller spinner was painted with alkyd paint. The rudder and fin received from Norway had to be refitted as their mounting brackets did not fit our fuselage. These parts had been painted with yellow primer. They were first painted with one brushed coat of aluminium primer, then two coats of green mixed from Teknodur paints and finally one brushed coat of aluminium paint was added. The red star was sketched according to photographs on page 29 in the book 'Red Star in the Sky', using the same shades as in the red stars on the fuselage.

Stands were built from pallets under the landing gear of the aircraft, so that it was elevated about one metre from the floor and it is possible to walk under it. An aircraft information board (in Finnish and English) for the display and a corresponding page in the museum's guidebook were produced.

March 6th is the anniversary of the Finnish Air Force and this year a gala was arranged at the aviation museum. There were 400 invited guests. The local newspaper Keskisuomalainen published an extensive article headed $A$ Cobra vintage fighter was completed in honour of the festivities.

The progress of the work was recorded in a project diary. Files were also gathered of the project's theory, the aircraft's deficiencies and the measures taken, the drawings of the parts made at the museum, marking stencils and the national markings, the transport of the aircraft and its assembly. Hundreds of photographs were taken: black and white, colour prints and slides, mostly for the museum archives but during the years the work was also photographed by many aviation enthusiasts and other visitors. The work was done by the restorer and aircraft mechanic Veikko Havimo and his restoring assistants, sheetiron worker and welder Pekka Nieminen and joiner Arvo Hirvonen. It took almost five years, but the result was good!

\section{WHAT HAVE WE LEARNED FROM THIS?}

Some observations: It is difficult to achieve the tolerance levels of the drawings; it is one thing to manufacture parts in an aircraft factory on a production line and quite another to make them alone by hand in a museum.

Compromises must be made in the choice of materials, because originals are not necessarily any longer available. One must also consider, how much effort it is wise to spend in order to obtain original materials (e.g. for a hatch inside the fuselage). Original manufacturing methods may be beyond our possibilities because of their size (e.g. large industrial presses) or for their quality (e.g. heating duralumin sheets). It is important to mark the replacement parts so that they will not get mixed up with the originals. The restoration report took shape during the work and decisions made at the various stages of the project are recorded in it.

In an aircraft which is being repaired to be displayed as a museum piece the aim is to preserve it in such a way as to serve the visitor's needs for information and experience. If the aim is to restore the aircraft to flight that would be something completely different. The two aims are as different as night and day.

The restorers must be willing to experiment and to have the courage to start new 
Rauni Valtonen \& Hannu VaLtonen

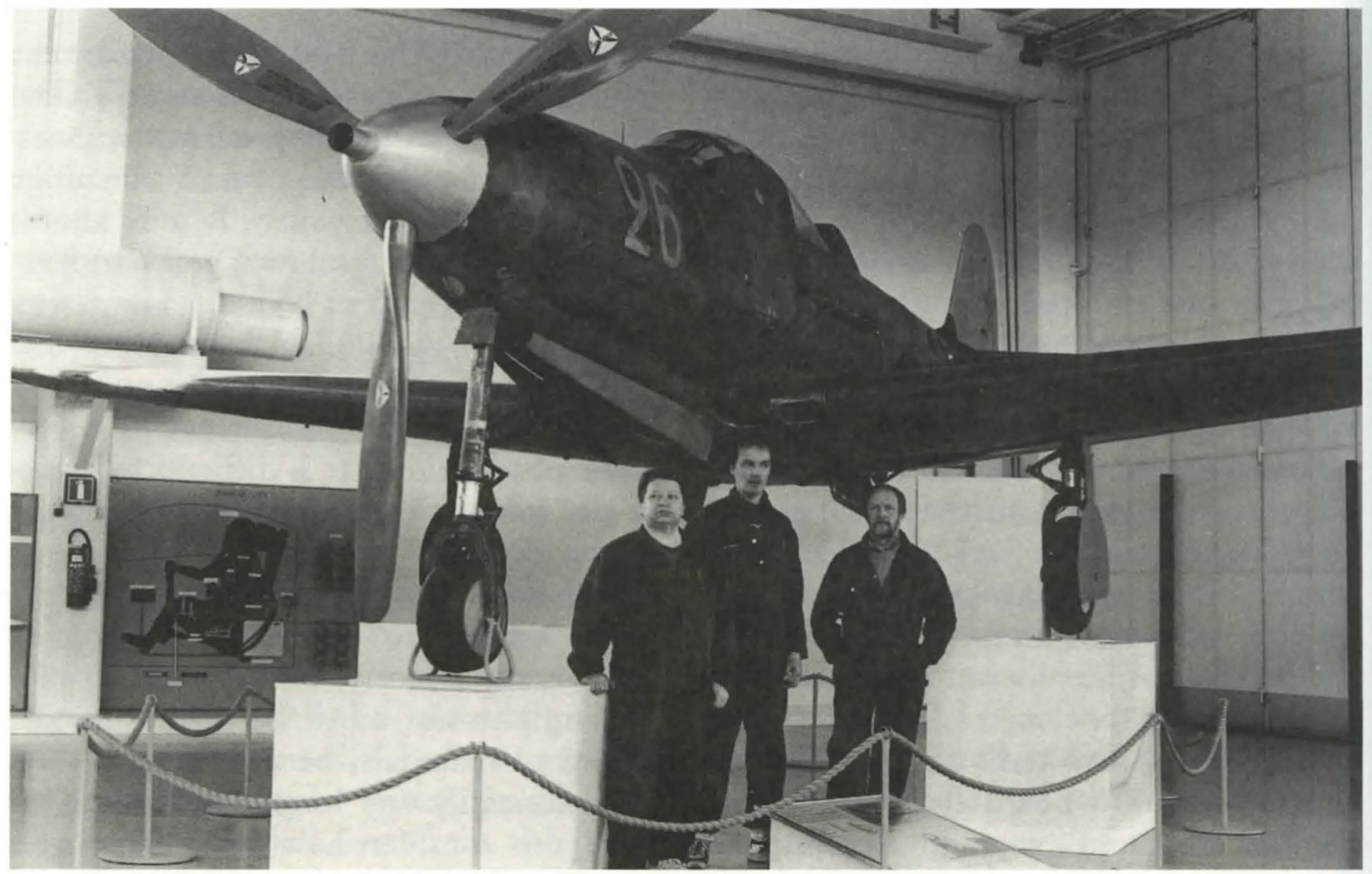

Fig 5. "Team Airacobra" as the workshop personnel jokingly called themselves, from the left: restoration assistants Arvo Hirvonen and Pekka Nieminen and restorer Veikko Havimo.

things. Part of the work must, in any case, be the result of experiment and one cannot have the skills and experience for everything.

The work was challenging and broke boundaries, but it brought with it the pleasure of success. It would be a good thing if there was an unbiased scale against which the degree of success could be estimated.
Translation by Timo Heinonen

Hannu Valtonen är chef for Keski-Suomen Ilmailumuseo

Adr: Tikkakoskentie 125

FIN-41160 Tikkakoski

Tel: +358143752125

Fax: +358143753620

homepage http://www.jiop.filksimuseol 